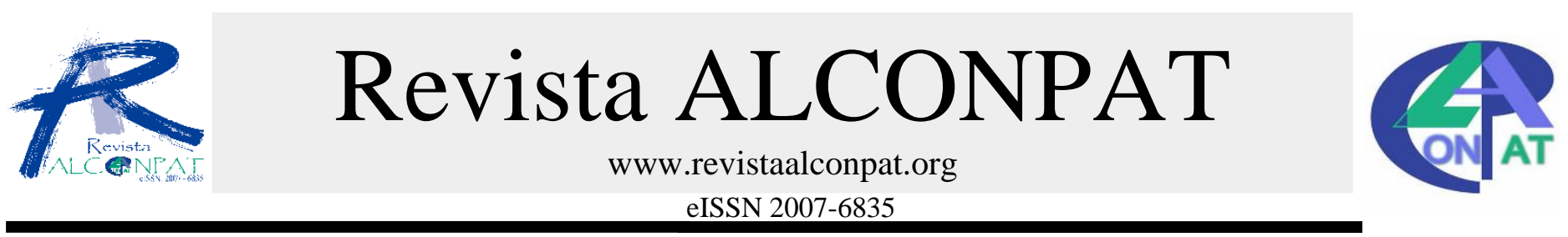

Revista de la Asociación Latinoamericana de Control de Calidad, Patología y Recuperación de la Construcción

\title{
Estudio de los daños y refuerzos necesarios para la recuperación del techo de la iglesia de Salsipuedes-Córdoba-Argentina
}

\author{
J. L. Gómez ${ }^{1}$, K. Klein ${ }^{1}$, G. Montiel ${ }^{2}$ \\ ${ }^{1}$ Facultad de Arquitectura, Urbanismo y Diseño Universidad Nacional de Córdoba, Argentina. \\ ${ }^{2}$ Miembro Alconpat, Argentina.
}

\begin{abstract}
Información del artículo
DOI:

http://dx.doi.org/10.21041/ra.v4

i3.68

Artículo recibido el 25 de Junio de 2014, revisado bajo las políticas de publicación de la Revista ALCONPAT y aceptado el 10 de Septiembre de 2014. Cualquier discusión, incluyendo la réplica de los autores, se publicará en el segundo número del año 2015 siempre y cuando la información se reciba antes del cierre del primer número del año 2015.
\end{abstract}

(C) 2014 ALCONPAT Internacional

Información Legal

Revista ALCONPAT, Año 4, No. 3, Septiembre - Diciembre 2014, es una publicación cuatrimestral de la Asociación Latinoamericana de Control de Calidad, Patología y Recuperación de la Construcción, Internacional, A.C., Av. Zamná No. 295 entre 61 y 63 Fraccionamiento Zamná No. 295 entre 61 y 63 Fraccionamien Yucalpetén, Mérida, Yucatán,

alconpat.int@gmail.com, Página Web: www.alconpat.org

Editor responsable: Dr. Pedro Castro Borges. Reserva de derechos al uso exclusivo No.042013-011717330300-203, 2013-011717330300-203, exSSN 2007-6835, ambos otorgados por el Instituto Nacional de Derecho de Autor. Responsable de la últim actualización de este número, Unidad de Informática ALCONPAT, Ing. Elizabeth Sabido Maldonado, Av. Zamná No. 295 entre 61 y 63 Fraccionamiento Yucalpetén, Mérida Yucatán, México, C.P. 97248 , fecha de publicación: 30 de septiembre de 2014

Las opiniones expresadas por los autores no necesariamente reflejan la postura del editor. Queda totalmente prohibida la reproducción total o parcial de los contenidos e imágenes de la publicación sin previa autorización de la ALCONPAT Internacional A.C.

\section{RESUMEN}

La Iglesia de Salsipuedes en la Provincia de Córdoba fue construida en el año 1875 y su techo está conformado por una estructura de madera, vigas reticulada y correas sobre las cuales se apoyan bovedillas cerámicas, capa de mortero y tejas musleras.

La Iglesia está inhabilitada por precaución debido a la aparición de fisuras en barras del reticulado y desprendimiento de trozos de mampostería en las cercanías del apoyo de las vigas principales. En este trabajo se estudia el estado tensional de las barras del reticulado y la materialización del apoyo de las vigas principales en los muros de mampostería.

Constatado el alto valor de las tensiones de trabajo de las barras con manifestaciones patológicas, como así también el inadecuado sistema de apoyo en la mampostería, se proyectan los refuerzos necesarios para lograr un funcionamiento de la estructura con un grado de seguridad adecuado.

Palabras clave: estructuras; madera; patología; patrimonio.

\section{ABSTRACT}

Salsipuedes the Church of the Province of Cordoba was built in 1875 and its roof is formed by a wooden structure, reticulate beams and straps which support ceramic arches tile mortar layer and tiling Legguards

The Church is disabled as a precaution due to the appearance of cracks in the grid bars and breaking away of pieces of masonry near the support of the main beams. In this work, we study the stress state of the grid bars and support the realization of the main beams in the masonry walls.

Confirmed the high value of the working stresses of the bars with pathological manifestations, as well as inadequate support system in the masonry, projecting reinforcements necessary for safe operation of the structure with a degree of security.

.Keywords: structures; wooden; pathology; patrimony.

Autor de contacto: Karin Klein (karinklein_2k@ hotmail.com) 


\section{INTRODUCCIÓN}

El presente trabajo surge de una intervención realizada en la actual Iglesia de la localidad de Salsipuedes, provincia de Córdoba, Argentina.

La Capilla fue construida en el periodo 1875-1885. Al derrumbe del techo original se lo rehace en 1894 tal como hoy se conserva.

La estructura de madera del techo de la iglesia está conformada por 22 vigas denominadas de par y nudillo apoyadas sobre muros de mampostería de ladrillo de $70 \mathrm{~cm}$ de espesor. Ver "Figuras 1 y 2".

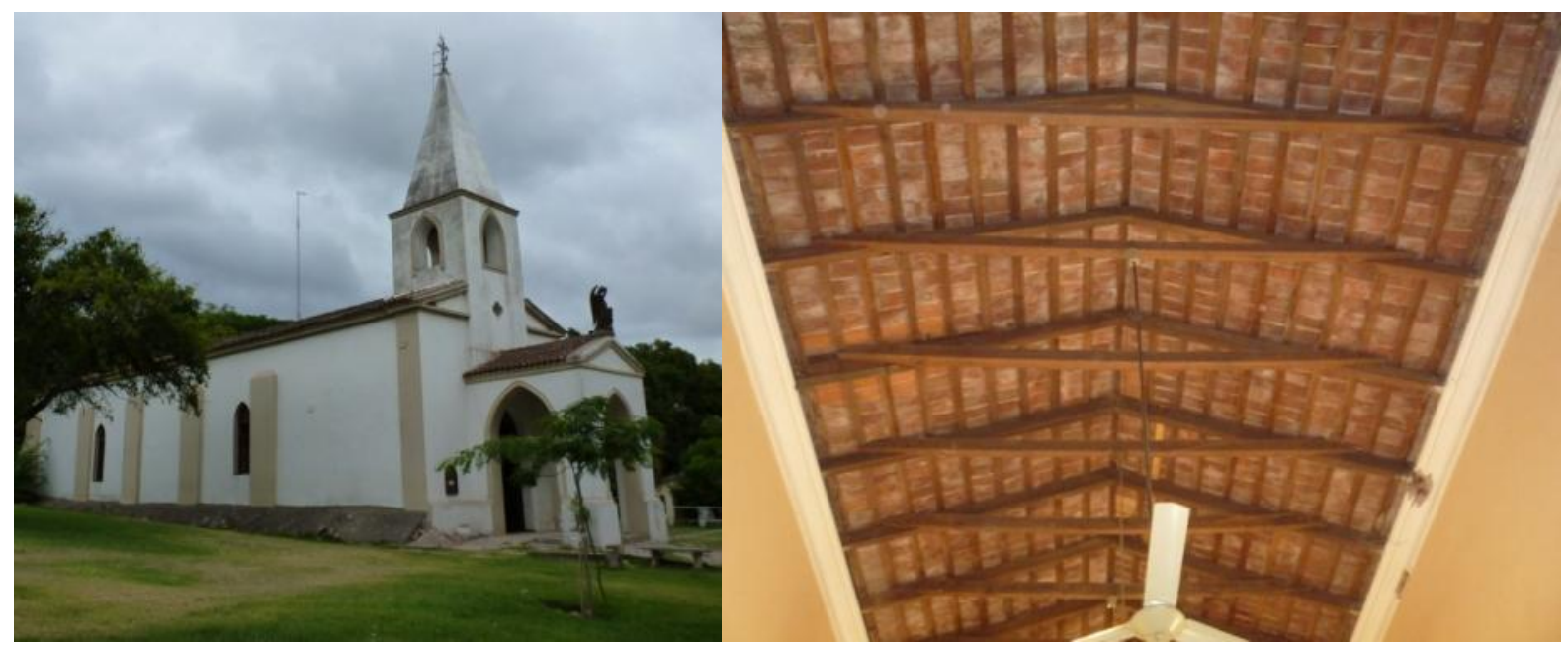

Figura 1. Vista exterior - interior de la Iglesia

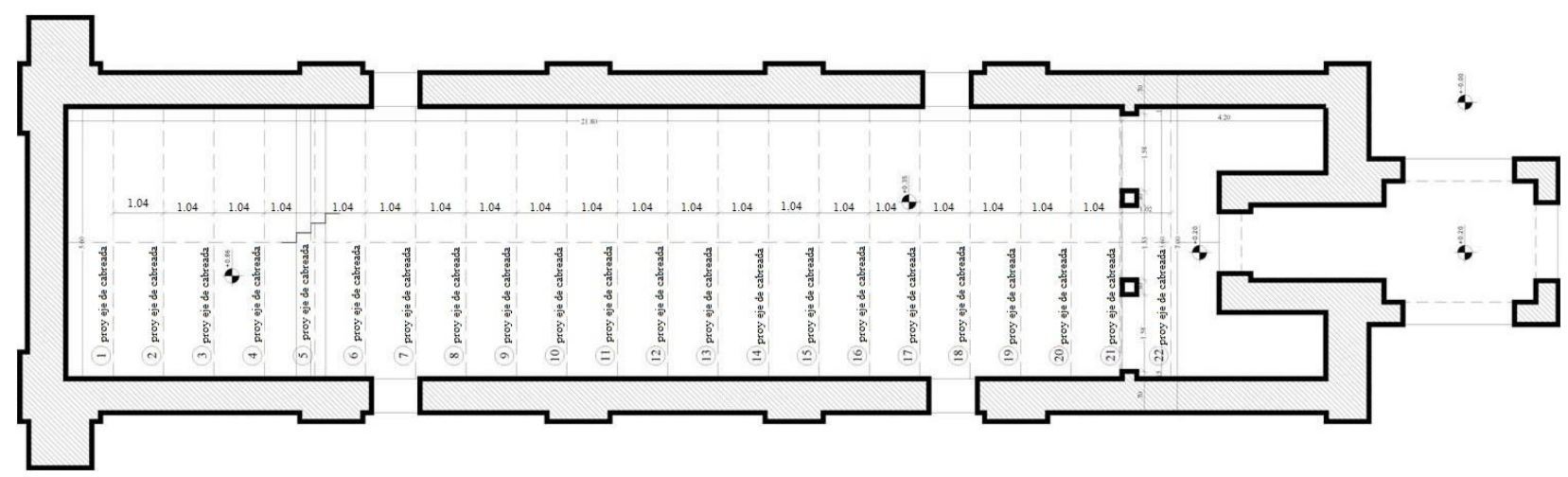

Figura 2. Planta Parroquia

Luego del relevamiento geométrico de la estructura se procedió a la tipificación de la madera utilizada en el Laboratorio de Dendrología y Xilología de la Facultad de Ciencias Forestales de la Universidad Nacional de Santiago del Estero. Simultáneamente se realizaron ensayos para conocer las características físico-mecánicas de las maderas en el laboratorio del Taller de Investigación de Diseño Estructural de la Universidad Nacional de Córdoba.

Una vez conocida la conformación de la estructura, el tipo de madera y sus características físico mecánicas se resuelve la misma con modernos procedimientos de análisis, realizando la verificación seccional siguiendo los lineamientos de la Norma Brasilera NBR 7190, determinando su grado de seguridad. 
En el momento de esta intervención la iglesia se encuentra inhabilitada por signos externos de manifestaciones patológicas de algunos elementos estructurales de madera y de sus apoyos. Del estudio del comportamiento estructural de las vigas de madera se proyectan refuerzos y se recomiendan terapias para las barras dañadas, orientadas a su conservación y mantenimiento.

\section{INVESTIGACIÓN DEL COMPORTAMIENTO DE LA ESTRUCTURA ACTUAL}

\subsection{Determinación de la conformación de cubierta y análisis de carga}

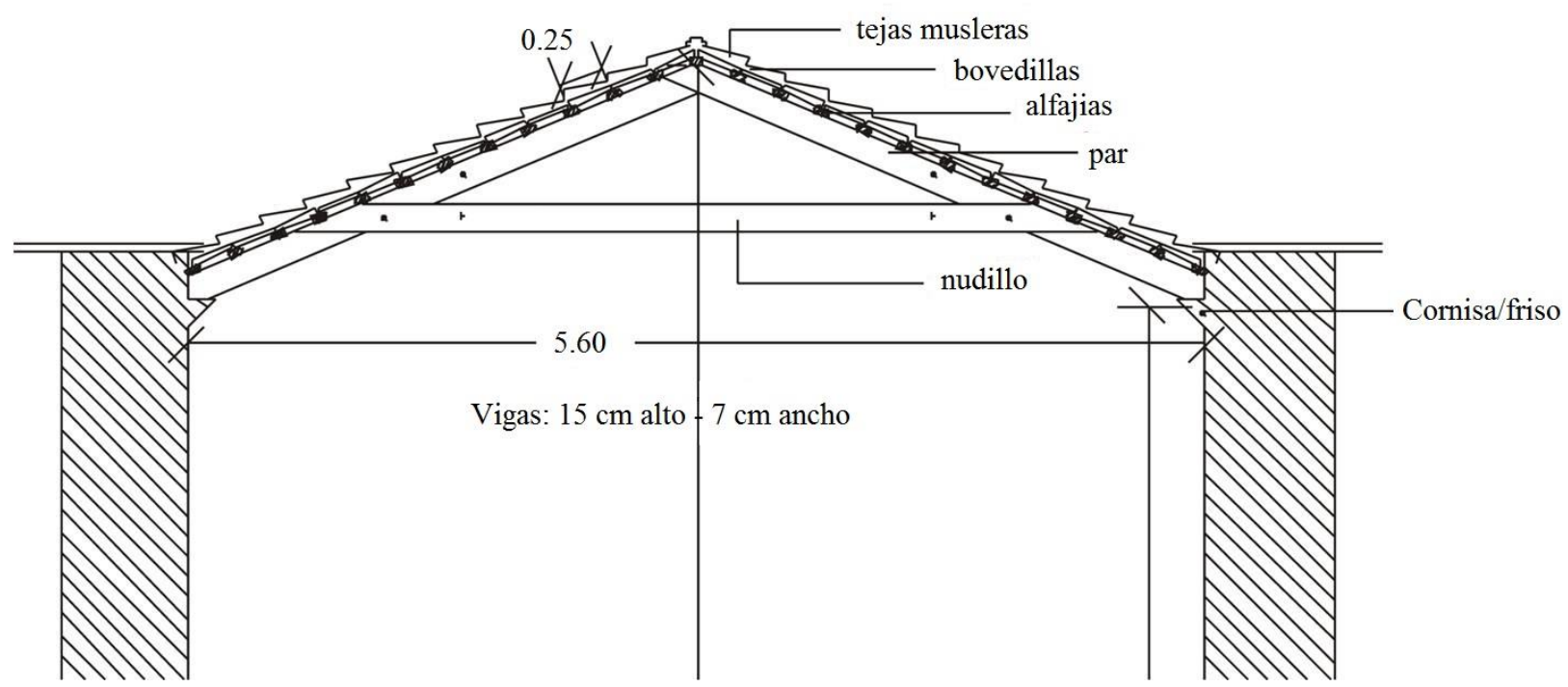

Figura 3. Esquema estructural original

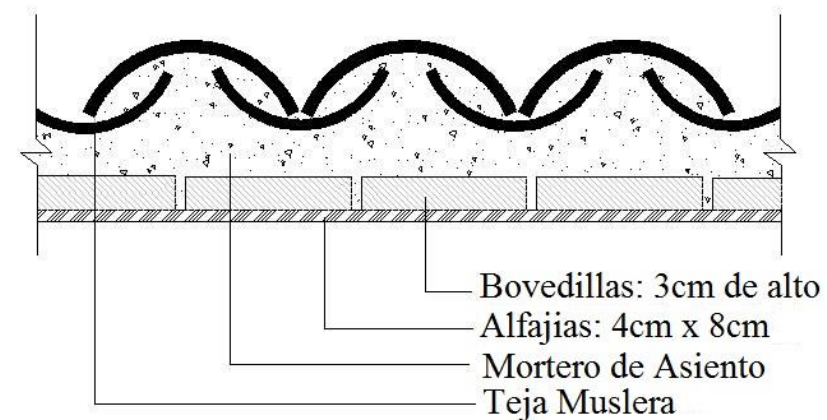

Figura 4. Detalle cubierta

Análisis de Cargas de Cubierta

Alfajías ------------------ $7,42 \mathrm{~kg} / \mathrm{m}^{2}$
Bovedillas ------------- 42,0 kg/m²
Carpeta $3 \mathrm{~cm}$----------- 66,0 kg /m²
Teja española ------------100,0 kg/m
Total ----------------------215,42 kg/m

Estudio de los daños y refuerzos necesarios para la recuperación del techo de la iglesia de... 
Carga Permanente por metro lineal incluido el peso propio g $=215,42+10.8=226,2 \mathrm{~kg} / \mathrm{m}$. Carga variable de uso $\mathrm{p}=18 \mathrm{~kg} / \mathrm{m}$. Se han impactado las cargas para cubrirse de las incertidumbres de los valores de las mismas (1).

$$
q_{c}=1,3 \times g+1,4 \times p=1,3 \times 226,2+1,4 \times 18=319,26 \mathrm{~kg} / \mathrm{m}
$$

\subsection{Resultados de la Identificación de la madera y determinación de las características físico mecánicas}

Las muestras fueron analizadas macro y microscópicamente y los resultados indican que corresponden a Gimnosperma, familia Pinaceae, Ge Pinus, especie: Pinus taeda.

El mismo es conocido vulgarmente como Pinotea, proviene de EE UU, del área de dispersión natural donde el crecimiento es muy inferior al que actualmente se obtiene de plantaciones comerciales de Argentina. Ver "Figura 5"
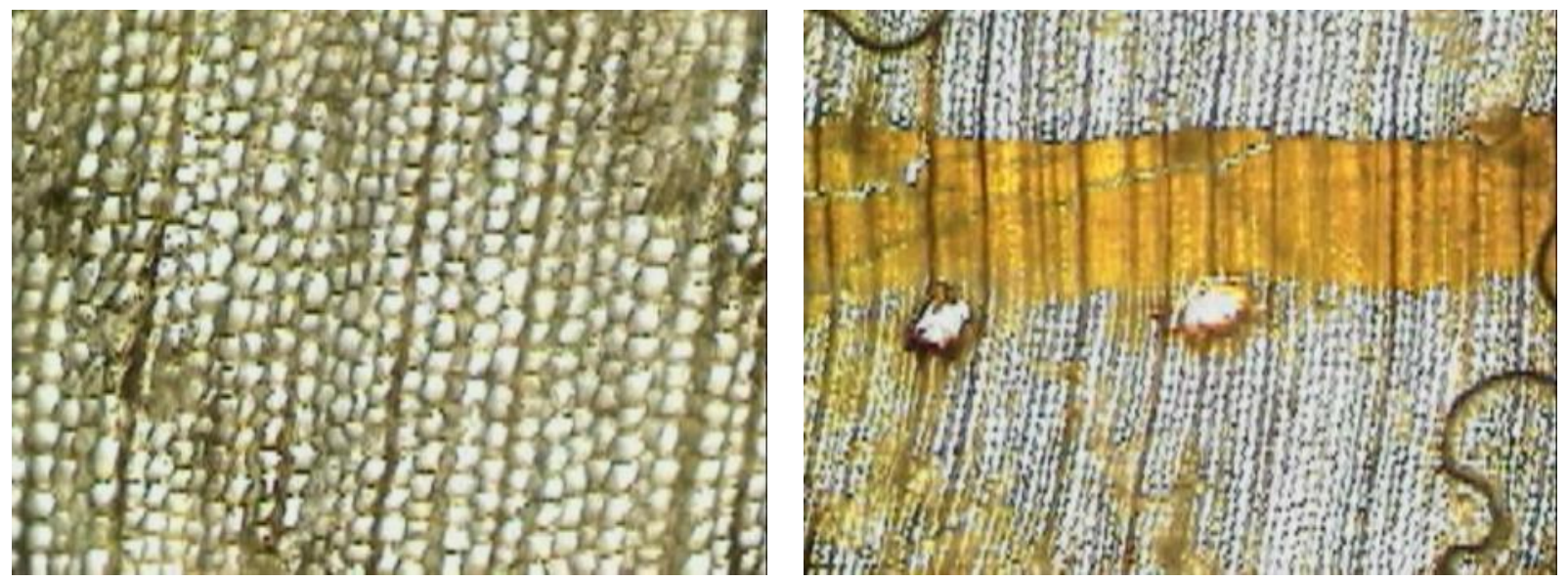

Figura 5. Muestra secciones transversal y tangencial

En el laboratorio del Taller de Investigación de Diseño Estructural de la Facultad de Arquitectura de la Facultad de Arquitectura de la UNC se determinaron las características físico-mecánicas de la Pinotea resultando:

Densidad básica: $\delta=695 \mathrm{~kg} / \mathrm{m}^{3}$

Resistencia característica de compresión paralela a la fibra: $\mathrm{f}_{\mathrm{c} 0 \mathrm{k}}=427 \mathrm{~kg} / \mathrm{cm}^{2}$

Módulo de Elasticidad Medio $\mathrm{E}_{\mathrm{m}}=211323 \mathrm{~kg} / \mathrm{cm}^{2}$

\subsection{Verificación Seccional de los pares y nudillo}

Se determina la resistencia de cálculo a compresión de la madera según la siguiente expresión (2)

$$
f_{\text {cod }}=\frac{\mathrm{kmod} 1 \times \mathrm{kmod} 2 \times \mathrm{kmod} 3 \times f_{\text {cok }}}{\gamma}=\frac{0,7 \times 0,8 \times 0,8 \times 427}{1,4}=136 \mathrm{~kg} / \mathrm{cm}^{2}
$$

El Módulo de elasticidad efectivo para calcular deformaciones será (3):

$$
E_{e f}=\operatorname{kmod} 1 \times \mathrm{kmod} 2 \times \mathrm{kmod} 3 \times \mathrm{Em}=0,6 \times 0,8 \times 0,8 \times 211323=81148 \mathrm{~kg} / \mathrm{cm}^{2}
$$

En sección 1-1 se hallan las solicitaciones máximas $\mathrm{M}=0,73$ tnm, N=1,913 t ver "Figura 6". 

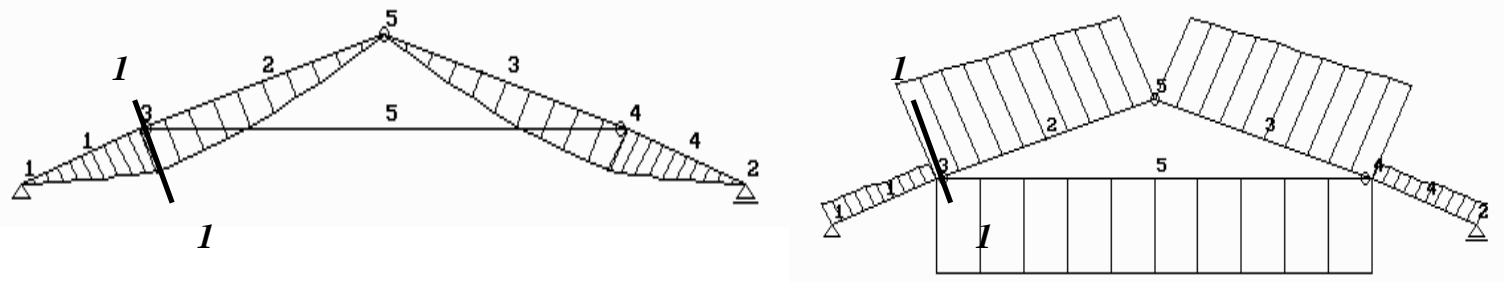

Figura 6. Diagramas momentos flectores y esfuerzos normales

Dimensiones de la sección $\mathrm{b}=7 \mathrm{~cm}, \mathrm{~d}=15 \mathrm{~cm}$ por la tanto $\mathrm{A}=105 \mathrm{~cm}^{2}$ y Módulo resistente $\mathrm{W}=262.5 \mathrm{~cm}^{3}$. La tensión de trabajo en la sección será: (4)

$$
\sigma_{t r}=\sigma_{N}+\sigma_{M}=\frac{1913 \mathrm{~kg}}{105 \mathrm{~cm}^{2}}+\frac{7300 \mathrm{kgcm}}{262,5 \mathrm{~cm}^{3}}=296 \mathrm{~kg} / \mathrm{cm}^{2}
$$

Se puede apreciar que la tensión de trabajo es muy superior a la resistencia de cálculo (296 $\mathrm{kg} / \mathrm{cm}^{2} \gg 136 \mathrm{~kg} / \mathrm{cm}^{2}$ ) hecho que queda evidenciado en los deterioros sufridos por este tipo de estructuras en dicha sección. Ver fotografías "Figura 7"

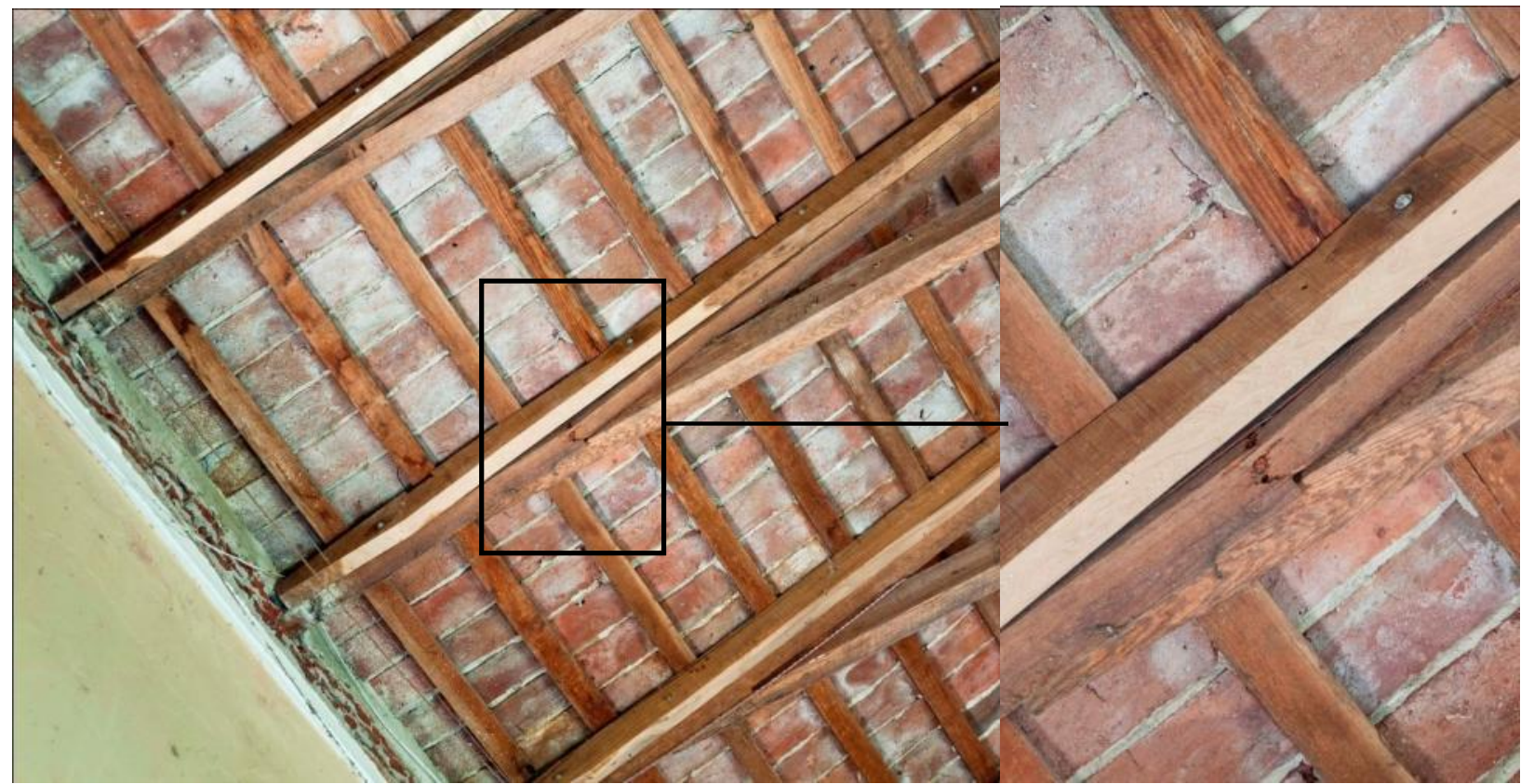

Figura 7. Manifestaciones patológicas relevadas en unión par y nudillo

\section{PROYECTO DE MODIFICACIÓN DE LA ESTRUCTURA Y SU RESOLUCIÓN}

Se proyecta adicionar una barra metálica que vincule los dos apoyos, para lo cual se emplea una barra de acero de $14 \mathrm{~mm}$ de diámetro de modo de no perturbar demasiado la calidad espacial interior original. Ver "Figura 8".

Estudio de los daños y refuerzos necesarios para la recuperación del techo de la iglesia de... 
Se procesa la nueva estructura con el mismo estado de cargas de la anterior obteniendo las nuevas solicitaciones. Ver "Figura 9"

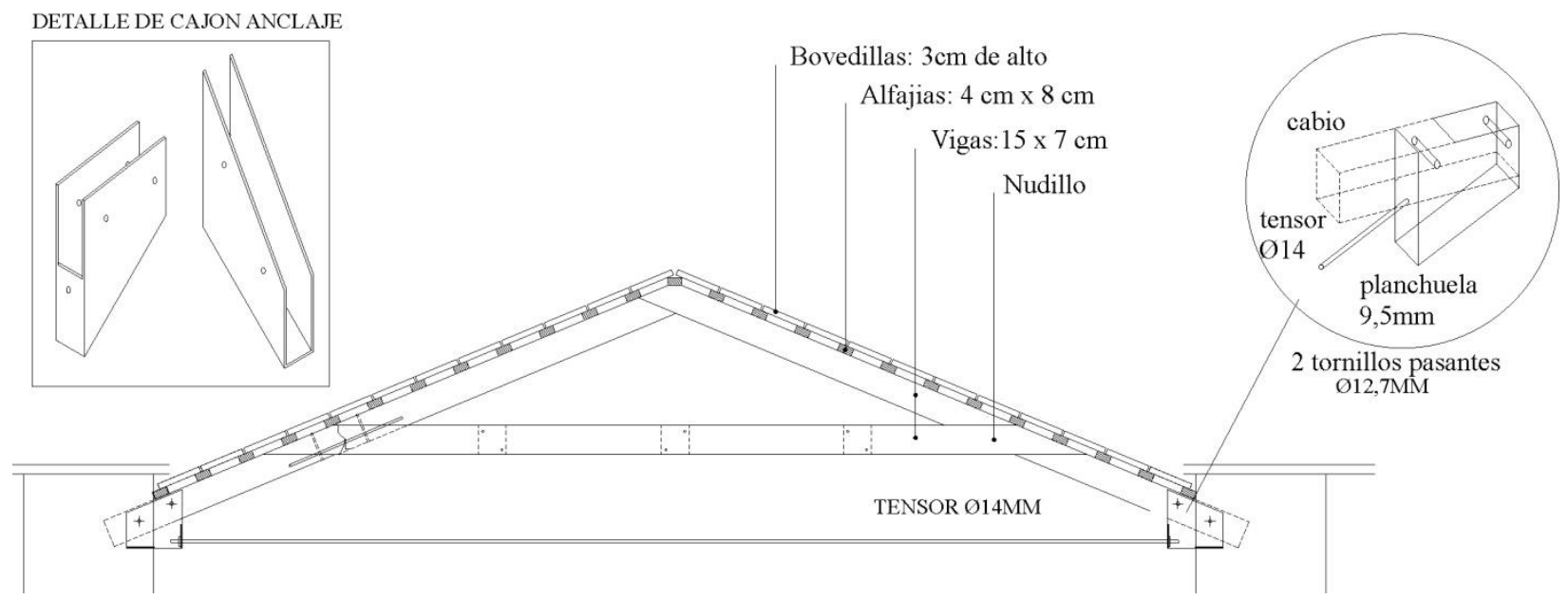

Figura 8. Nuevo esquema estructural y detalle anclaje del tensor
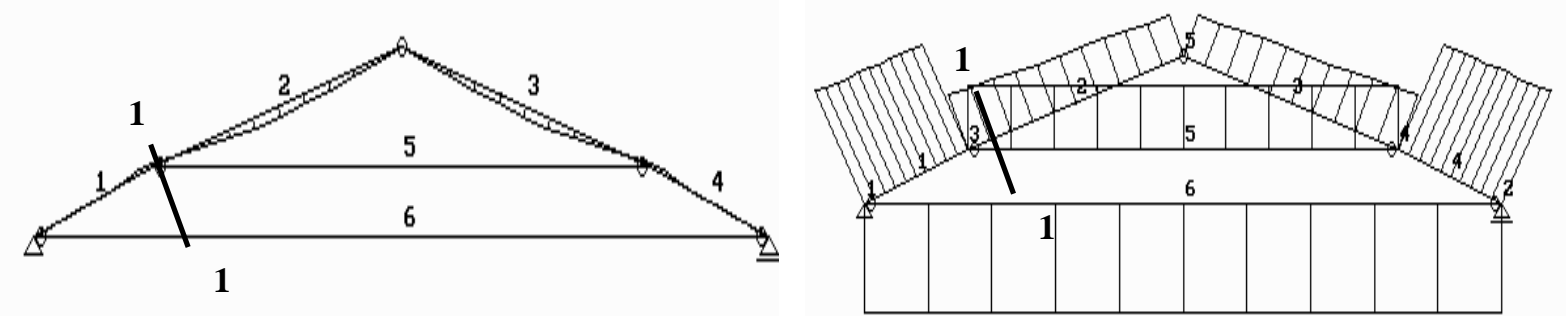

Figura 9. Diagramas de momentos flectores y esfuerzos normales

\subsection{Verificación Seccional de los pares y nudillo}

Verificación de pares. Solicitaciones en Barra 1, M $=0.058 \mathrm{tnm}, \mathrm{N}=1,86 \mathrm{t}$

La tensión de trabajo en B1 de la estructura modificada será (5)

$$
\sigma_{t r}=\sigma_{N}+\sigma_{M}=\frac{1860 \mathrm{~kg}}{105 \mathrm{~cm}^{2}}+\frac{5800 \mathrm{kgcm}}{262,5 \mathrm{~cm}^{3}}=39,82 \mathrm{~kg} / \mathrm{cm}^{2}<<f_{\text {cod }}=136 \mathrm{~kg} / \mathrm{cm}^{2}
$$

Solicitaciones en Barra 2, M = 0,125 tm, $\mathrm{N}=0,79 \mathrm{t}$

La tensión de trabajo en B2 será (6)

$$
\sigma_{t r}=\sigma_{N}+\sigma_{M}=\frac{790 \mathrm{~kg}}{105 \mathrm{~cm}^{2}}+\frac{12500 \mathrm{kgcm}}{262,5 \mathrm{~cm}^{3}}=55,13 \mathrm{~kg} / \mathrm{cm}^{2}<<f_{\text {cod }}=136 \mathrm{~kg} / \mathrm{cm}^{2}
$$

Ambas tensiones de trabajo son menores que la resistencia de cálculo.- 
Verificación de nudillo. La Barra 5 que en la estructura original trabajaba a tracción, en el nuevo esquema proyectado está solicitada a compresión con un valor $\mathrm{N}=1,008 \mathrm{t}$ con una esbeltez importante determinada a partir de su longitud $=380 \mathrm{~cm}$ y radio de giro $i_{\min }=4,08 \mathrm{~cm} \mathrm{(7)}$

$$
\lambda=\frac{l}{i_{\min }}=95>80
$$

Por este motivo se diseña la incorporación de una barra apareada de igual sección vinculada mediante separadores discontinuos para asegurar su correcto comportamiento a compresión. Ver detalle del nuevo nudillo en "Figuras 10 - 11"

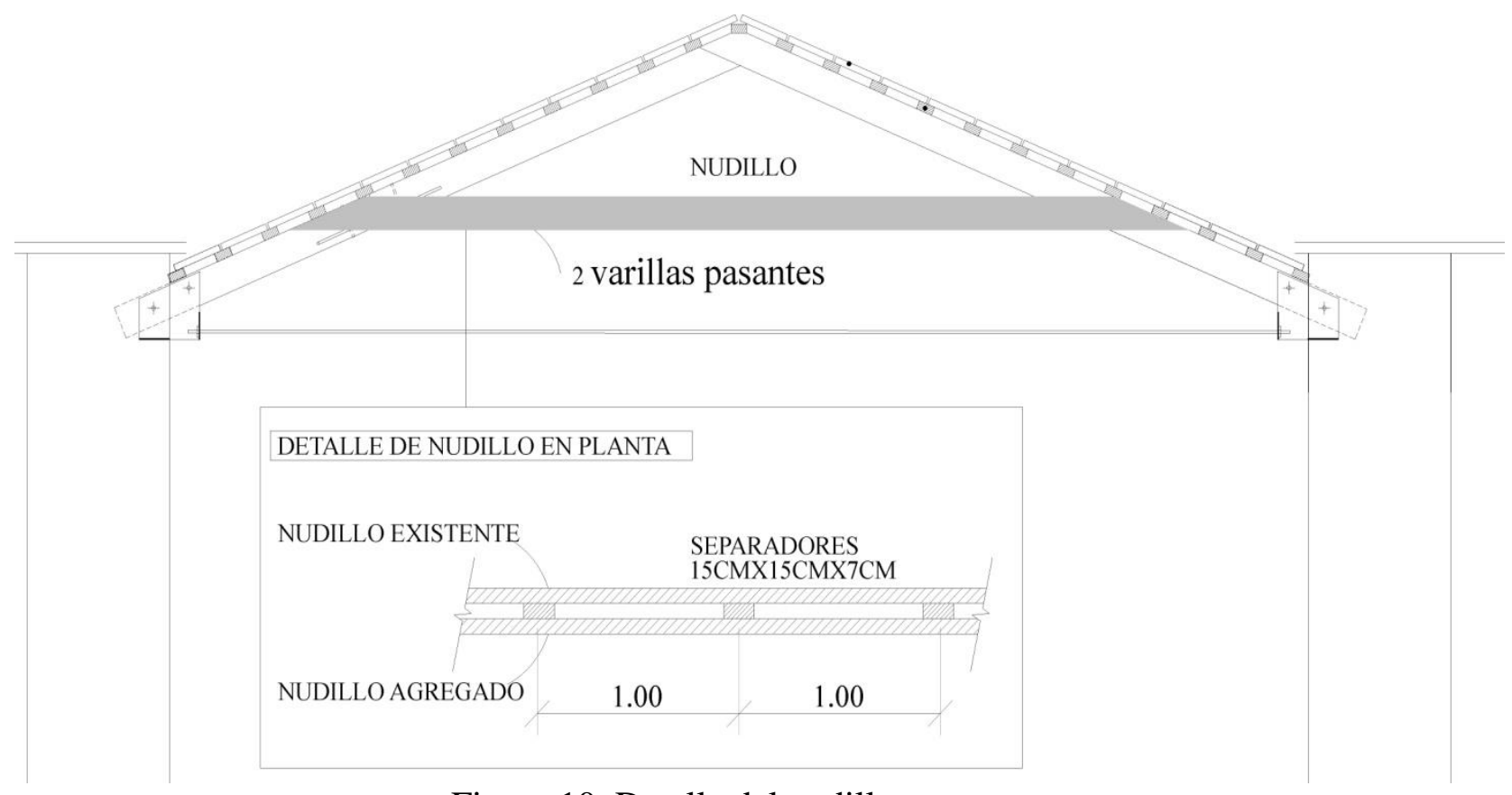

Figura 10. Detalle del nudillo propuesto

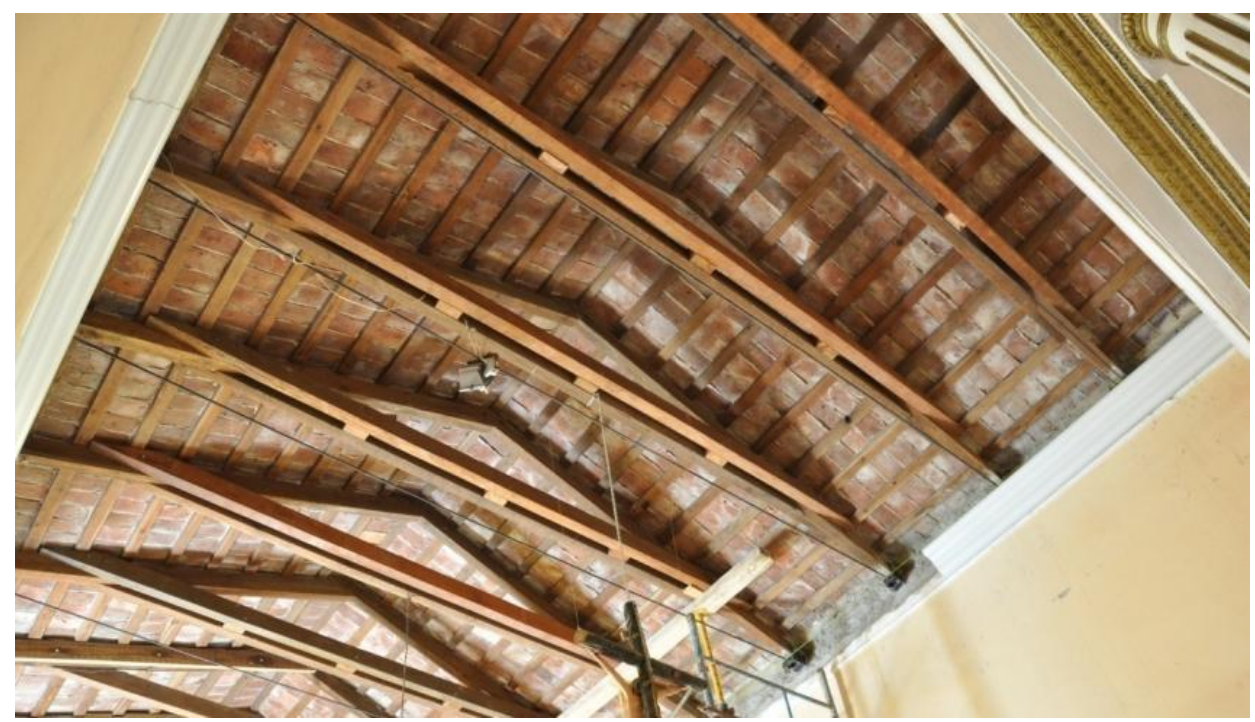

Figura 11. Ejecución del nudillo paralelo 


\section{RECOMENDACIONES DE ACTUACIÓN EN BARRAS DAÑADAS}

En la capilla se relevaron distintos tipos de daños que se podrían clasificar en los siguientes, por un lado pudrición del par en las zonas de los apoyos y por otro, fisuras paralelas a las fibras tanto en pares como en nudillo y barras quebradas en la unión par y nudillo.

Al comenzar los trabajos de colocación de la caja metálica receptora del tensor se encontró una nueva manifestación patológica, la pudrición del par en la zona de contacto con la mampostería. Ver "Figura 12". La terapéutica curativa adoptada para este caso fue la transformación de la sección dañada por otra mixta de madera y resina epoxi. Se eligió esta solución ya que la sustitución de las piezas dañadas era muy compleja y difícil de conseguir el mismo tipo de madera en el mercado actual.

El proceso de recuperación consiste en una limpieza profunda de la zona afectada, la unión entre el mortero epoxídico y la madera sana es reforzada insertando varillas de acero en perforaciones de un diámetro $2 \mathrm{~mm}$ mayor que el de la varilla para que la resina epoxi penetre en dicha cavidad y por último se procede a la reconstrucción de la sección mixta rellenando con mortero epoxi hasta recuperar las dimensiones originales.

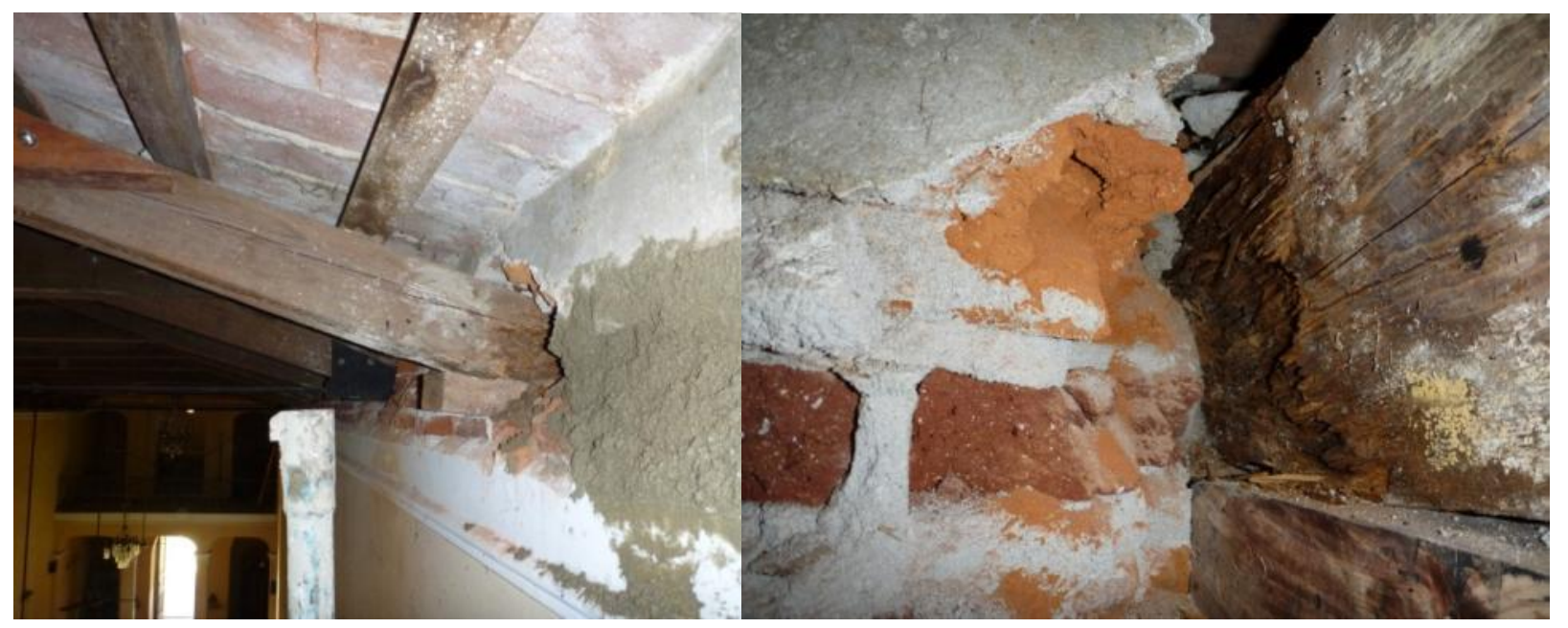

Figura 12. Imágenes de patología del par en los apoyos

Por otro lado para las otras manifestaciones se descartó una incremento de las características físico mecánicas con escuadras de madera o acero mediante operaciones de grapado ó cocido ya que por tratarse de una estructura a la vista de una edificación de valor patrimonial se debía mantener la calidad espacial interior y la intervención debía tener un impacto visual mínimo.

En los pares con fisuras paralelas a las fibras y muy profundas se procedió luego de su limpieza a la colocación de resina epoxi asegurándose su ubicación mediante varilla roscada perpendicular a las fibras ajustadas con arandela y tuerca fresadas para mejorar su terminación.

Para los casos de vigas quebradas pero madera sin pudrición se utiliza el cocido interno con varillas de acero y resina epoxi. Se recuerda que estos daños, fisuras y quebraduras se han producido por las solicitaciones del Sistema estructural anterior y que en la propuesta estructural actual las mismas disminuyen notablemente. Ver "Figura 13".

Así mismo cabe aclarar que durante el proceso de ejecución de la recuperación por tratarse de un edificio patrimonial las cargas del techo no fueron retiradas sino que se implementó un sistema de puntales telescópicos a ambos lados de cada cabriada produciendo presión interior sobre las 
correas, para alivianar las cargas que luego de realizar el pretensado del tensor de refuerzo se retiraron para garantizar el cambio de sistema estructural.

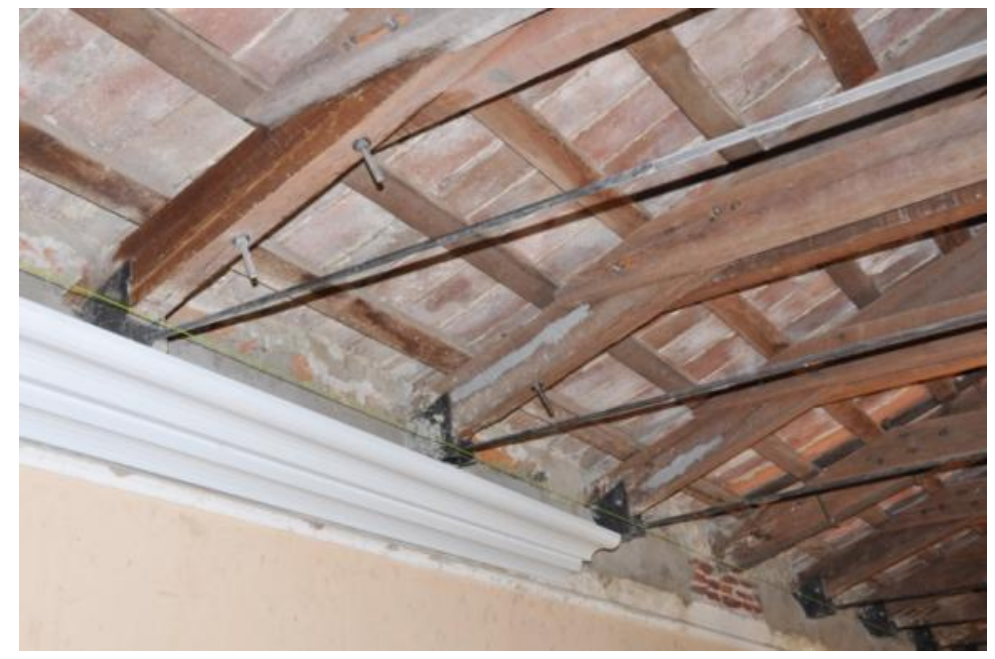

Figura 13. Reparación de fisuras paralelas

\section{CONCLUSIONES}

El análisis estructural, la verificación del sistema estructural original explican el motivo de los daños ocurridos en los pares y en el apoyo de los mismos que motivaron la inhabilitación de la iglesia.

El proyecto de recuperación que se está actualmente concluido, modificó el comportamiento de los elementos estructurales haciendo que los mismos trabajen con un grado de seguridad adecuado logrando una intervención respetuosa del valor patrimonial de la obra. "Figura 14".

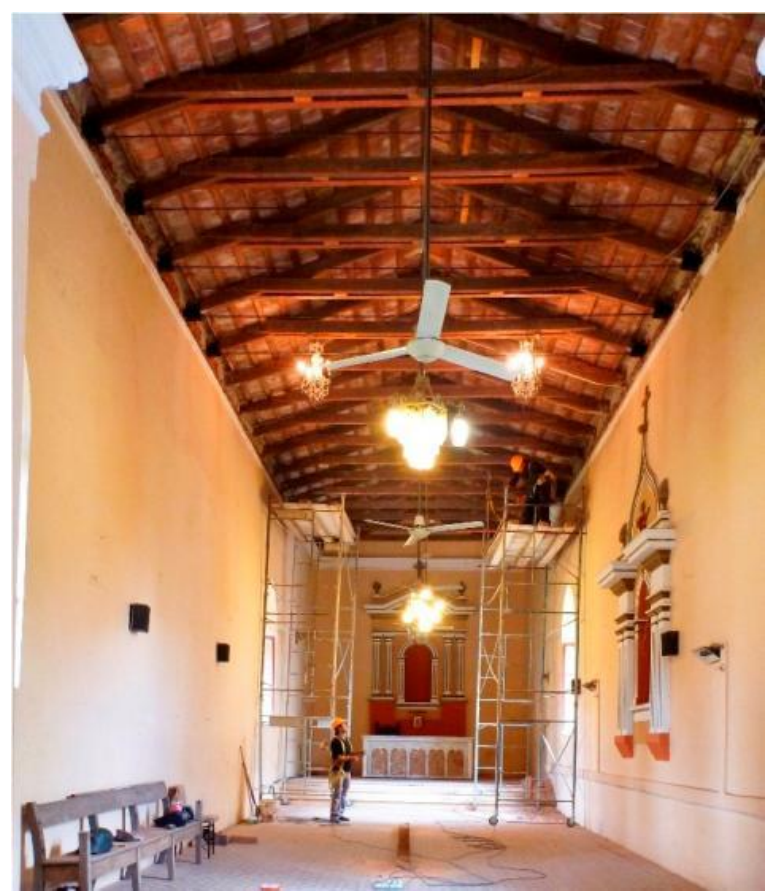

Figura 14. Recuperación de la Capilla

Estudio de los daños y refuerzos necesarios para la recuperación del techo de la iglesia de... 
Revista ALCONPAT, Volumen 4, Número 3, Septiembre - Diciembre 2014, Páginas 182 - 191

\section{AGRADECIMIENTOS}

Los autores desean agradecer a la Comisión Directiva de la Parroquia Nuestra Señora del Rosario de Salsipuedes que confió en nuestro servicio y brindó toda la colaboración para el relevamiento, diseño y ejecución de los trabajos de recuperación de la Iglesia.

\section{BIBLIOGRAFÍA}

Argüellez Alvarez, R., Martitegui, F. Arriaga (1996), “Estructuras de madera, Diseño y cálculo" (Madrid, España: Graficas Palermo)

Associaçao brasileira de normas técnicas NBR 7190 (1997), "Projeto de estruturas de madeira" (Río de Janeiro, Brasil: ABNT)

Gómez, J. L., (2000), “Estructuras de madera” (Córdoba, Argentina: Ingreso)

Lozano Apolo, G., Lozano Martinez Luengas, A. (1995) "Técnicas de Intervención en el Patrimonio Arquitectónico" Gijón, España: Mercantil Asturias 